Rabaska

Revue d'ethnologie de l'Amérique française

\title{
La Politique du patrimoine culturel du Québec
}

Numéro 1, 2003

URI : https://id.erudit.org/iderudit/039383ar

DOI : https://doi.org/10.7202/039383ar

Aller au sommaire du numéro

Éditeur(s)

Société québécoise d'ethnologie

ISSN

1703-7433 (imprimé)

1916-7350 (numérique)

Découvrir la revue

Citer ce document

(2003). La Politique du patrimoine culturel du Québec. Rabaska, (1), 113-113.

https://doi.org/10.7202/039383ar d'utilisation que vous pouvez consulter en ligne.

https://apropos.erudit.org/fr/usagers/politique-dutilisation/ 


\section{Place publique}

\section{Points de vue}

\section{La Politique du patrimoine culturel du Québec}

En novembre 2000, le groupe présidé par M. Roland Arpin déposait sa proposition visant à doter le Québec d'une politique du patrimoine culturel. Rabaska a demandé à deux ethnologues, préoccupés par cette question, de livrer leurs points de vue sur ce rapport, qui se présentait comme suit :

Notre Patrimoine, un présent du passé. Proposition présentée à Madame Agnès Maltais, ministre de la Culture et des Communications, par le Groupe-conseil sous la présidence de Monsieur Roland Arpin. [Québec, Gouvernement du Québec], Le Groupe-conseil sur la Politique du patrimoine culturel du Québec, novembre 2000, XXX-240 p. Annexes (I : Curriculum vitae des membres du Groupe-conseil ; II : Liste des organismes et des personnes rencontrées ; III : Bibliographie, Liste des documents reçus, Liste des documents consultés), photos, 17 tableaux. ISBN 2-550-36748-0.

\section{En marge d'une libre lecture}

ANDRÉ Desvallées

Musée national des Arts et traditions populaires, Paris

Entre 1999 et 2000 Roland Arpin a conduit la réflexion et la rédaction d'un groupe de travail qui a débouché sur un bilan et une somme de propositions, auxquels il ne semble rien manquer, en vue d'améliorer la gestion du patrimoine québécois. Du fait de la richesse de ce bilan ${ }^{1}$, il serait hors de ma portée de reprendre tous les problèmes soulevés par cet examen systématique de la situation patrimoniale au Québec. Ayant donc à choisir, je m'en tiendrai à quelques points qui peuvent faire problème, sur lesquels je pourrai appliquer mes critiques. Parmi tous ceux-ci, j'examinerai surtout ceux qui concernent le niveau de responsabilité, individuel ou collectif, à l'égard du patrimoine, mais auparavant, je jetterai un regard sur ce qui touche au domaine couvert

1. Encore que certaines redites, parfois simple variation dans la formulation d'un même thème, auraient pu l'alléger, dues sans doute au caractère collectif de la rédaction. 